\title{
سمات نحت الأطفال بين الطبيعة والخيال *
}

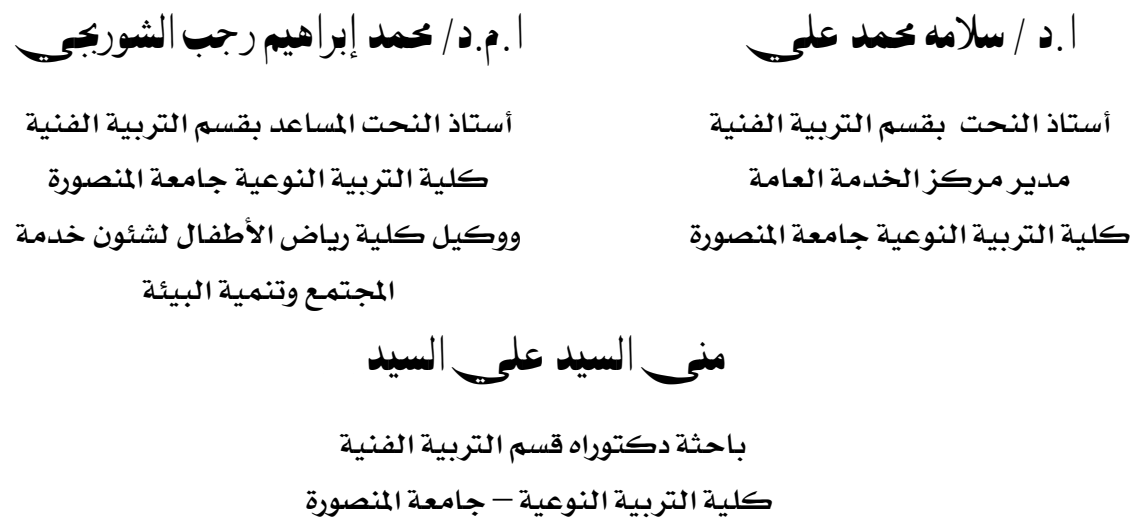

مجلة بحوث التربية النوعية - جامعة المنصورة

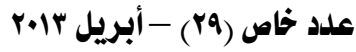




\section{سمات نحت الأطفال بين الطبيعة والخيال}
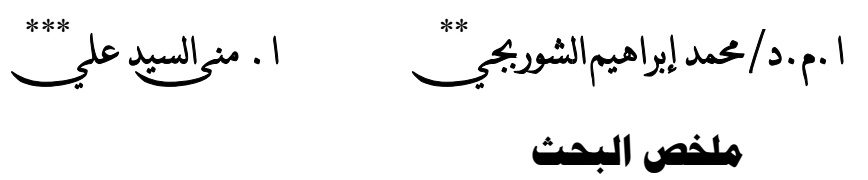

$\underbrace{*}$ / سلامهمحمد علم /

يعتبر التعبير الفنسى المجسم للأطفال هـو احسد مظـاهر الفـن التشكيلى ووسيلة مـن وسـائل

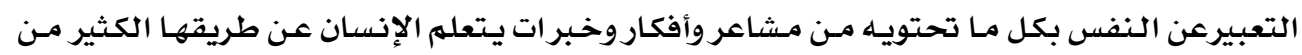

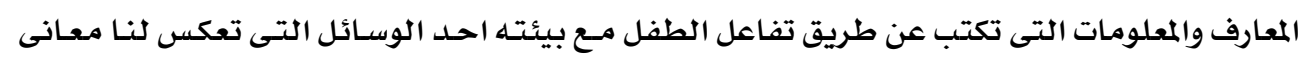

الحياة التى نعيشها.

ويستمدد الفن فاعليته لقدرتـه على مخاطبـة تفكير الطفل وإحسـاسـه ويسـاعد الأطفال عن

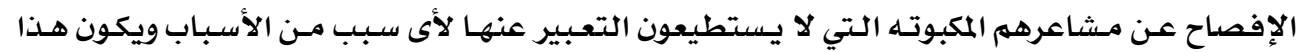

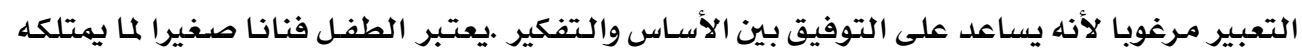

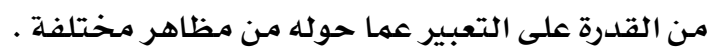

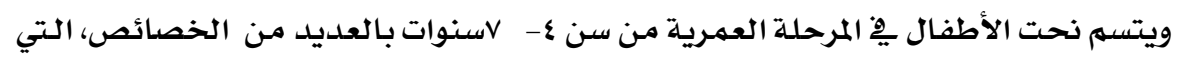

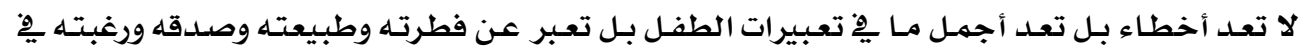

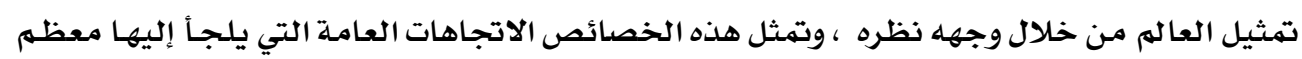

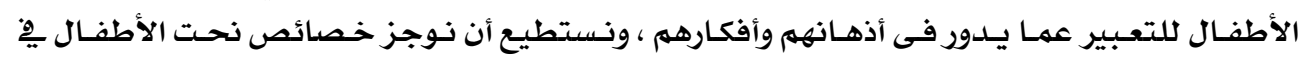

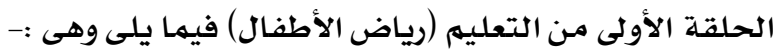

$$
\begin{aligned}
& \text { • التلقائية } \\
& \text { • • } \\
& \text { • }
\end{aligned}
$$

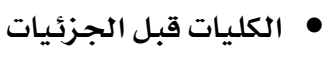

$$
\begin{aligned}
& \text { • الطبيعة الهندسية الجية الجيات } \\
& \text { • • التعبير عن الذات الطبيعة الذيات } \\
& \text { • • } \\
& \text { • • الرمزيلة }
\end{aligned}
$$

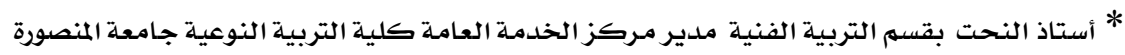

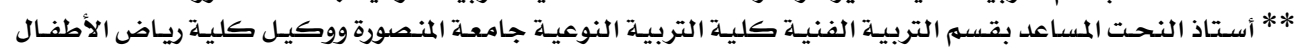

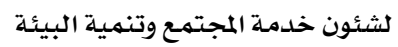

**** * *احثة دكتوراه قسمى التربية الفنية - كلية التربية النوعية - جامعة المنصورة 
سمات نحت الأطفال بين الطبيعة والخيال

\title{
Sculpture attributes children between nature and imagination
}

\author{
Dr. Slama Mohammed Ali * Dr. Mohamed Ibrahim ElShorbagy ** \\ Mona El-Sayed Ali El-Sayed *
}

\begin{abstract}
Summary
The artistic expression surround for children is one of the manifestations of Fine Art and a means of means Altobeiran self with all its feelings and thoughts and experiences to learn the human way a lot of knowledge and information, which writes through interaction child with his environment one means which reflect our meaning of life in which we live.

And draws art effectiveness for its ability to address the thinking child and the sense and helps children to disclose their feelings pent which can not be expressed any reason and this expression is desirable because it helps to reconcile the foundation and think. Considered child artist small what possessed the ability to express what turned him from different appearances.
\end{abstract}

And a sculpture of children in the age group from the age of 4-7 years with many of the properties, which are not errors, but are the most beautiful in the expressions of the Child but express his nature, nature and sincerity and desire to represent the world through his point of view, and represent these characteristics general trends resorted to most children to express what is in their minds, and Nstttaa summarize the properties sculpture of children in the first episode of education (kindergarten) as follows, namely: -

- Automatic

- Misrepresentation

- Innocence

- Colleges before molecules

- Geometry

- Self-expression

- Imagination

- Avatar

* Professor of Sculpture, Faculty of Specific Education, Mansoura University

**Associate Professor of Sculpture, Faculty of Specific Education, Mansoura University

* Bachelor of Specific Education, (Art Education) Mansoura University 


\section{سمات نحت الأطفال بين الطبيعة والخيال}

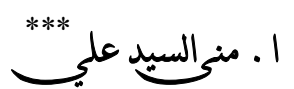

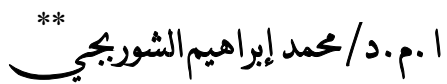

*

مقدمهة:

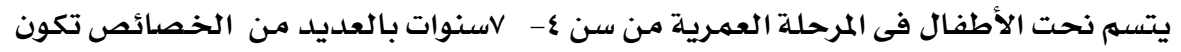

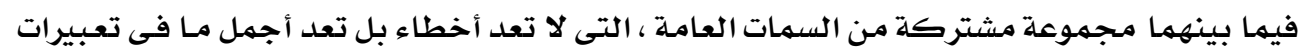

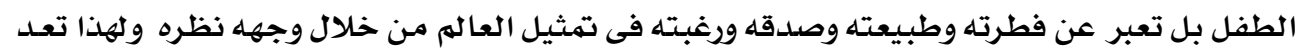

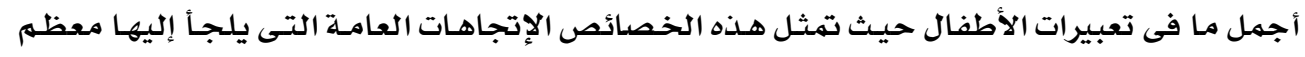

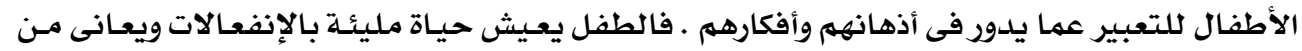

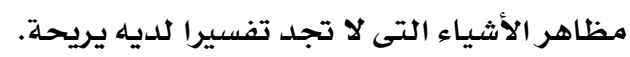

وقد حدد البحث أهم سهمات نحت الأطفال يِّ الحلقـة الأولى مـن التعليم (ريـاض الأطفال)

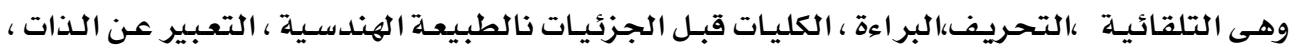

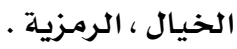

أولاُ التلقائية :- الرئة -

هى " سمهه مميزه لنحت الأطفال ، وتعنى التعبير عن الذات بغير أكراه ، فهي نشاط داخلي

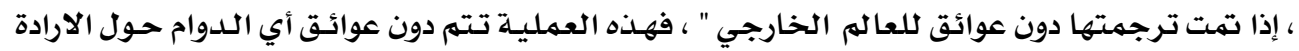

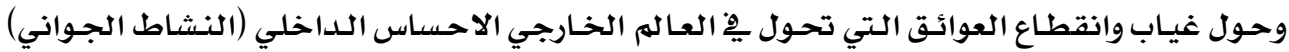

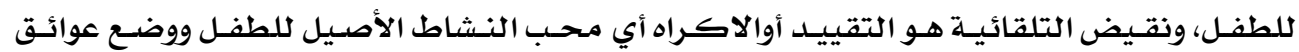
تحول دون ظهوره الي حيز الواقع.

يتميز التجسيهم عند الأطفال بالتلقائية بشكل عام حيث تتم بناءا علي منطق الطفل النـابع

من داخله وعالمه المميز، ولكل طفل عالمه وخصائصده التي يتميز بها.

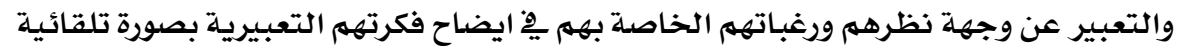

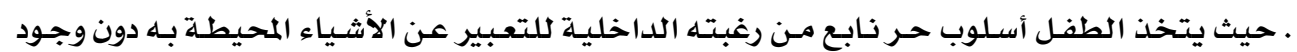

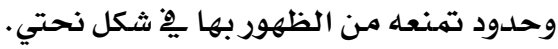

* أستاذ النحت بقسم التربية الفنية مدير مركز الخدمة العامة كلية التربية النوعية جامعة المنصورة

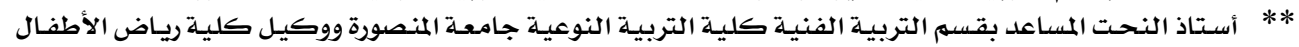
لشئون خدمة المجتمع وتتمية البيئة *** * *احثة دكتوراه قسم التربية الفنية - كلية التربية النوعية - جامعة المنصورة 


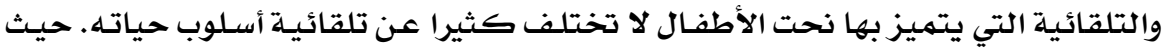

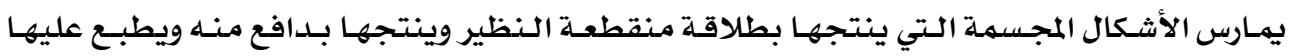
طفولته المتحررة .

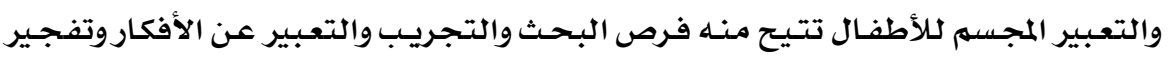

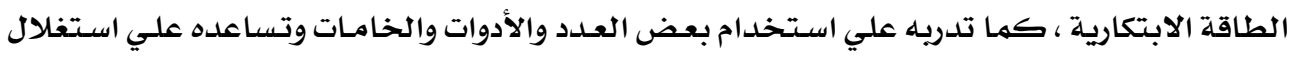

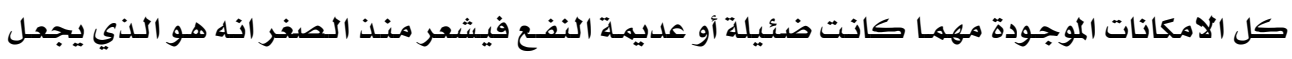

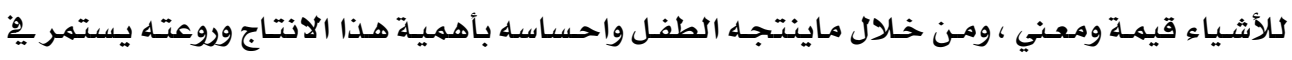

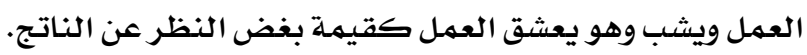

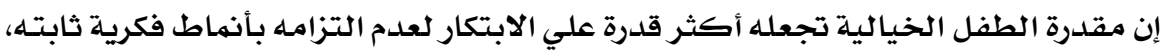

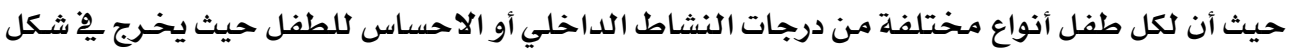

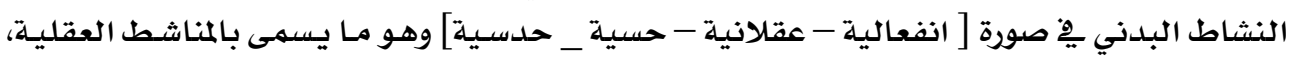

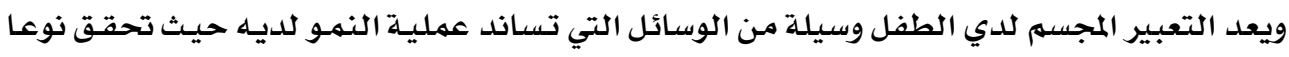

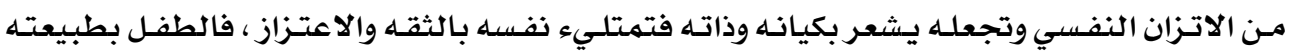

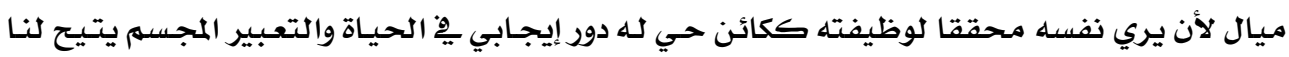

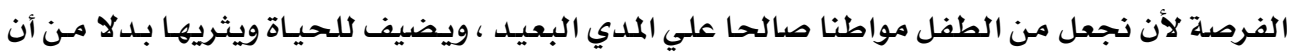
يتقاعس بحجة عدم الامكانات.

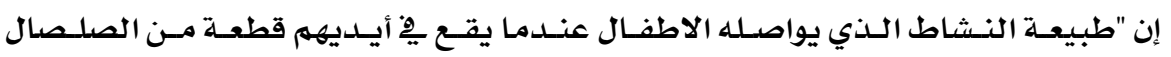

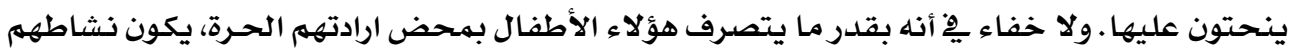

تلقائيا"(').

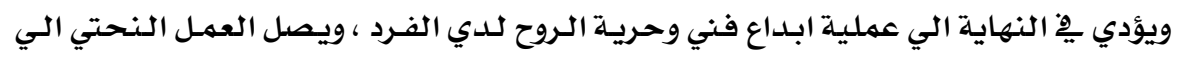

التعبير ، ويري أفكاره تترجم إلي حقيقة مماثلة.

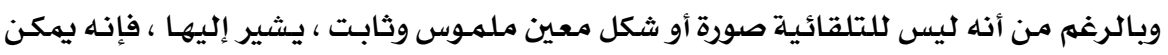

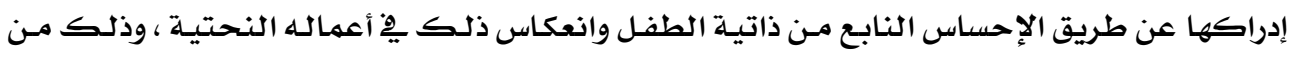

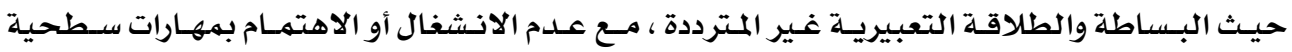
جامدة.

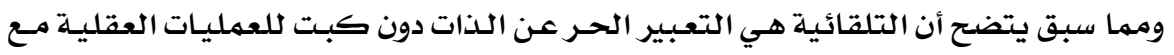

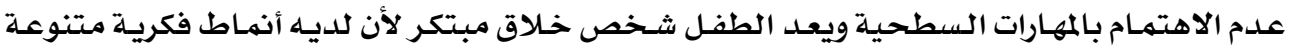

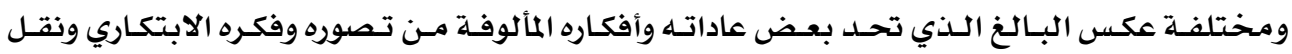
تلقائية الطفل كلما تقدم بـه العمر.

هريرت ريد: التربية عن طريق الفن،ترجمة: عبد العزيز جاويد ،ا لهيئة العامة للكتاب ،القاهرة،1997، ص $10 \mathrm{~V}$. 
ولذلك وجب علي المحيطين بالطفل أن يشجعوا التلقائية يُ نحت الأطفال التي تميز روح

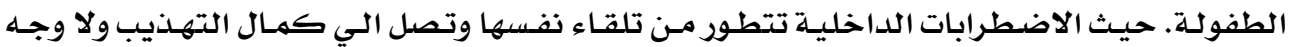
لمقاومتها أن تولد إلي حيز الوفود الوفران الخارجي.

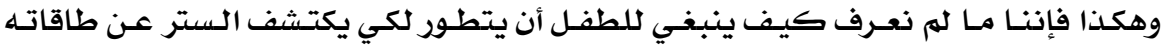

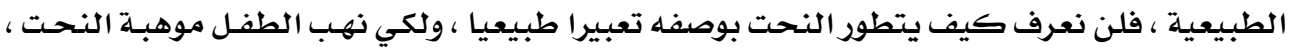

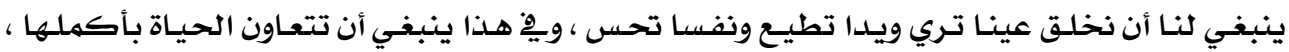

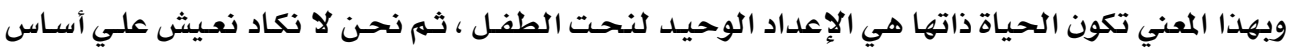

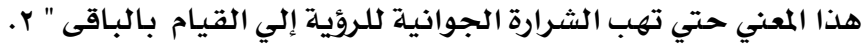

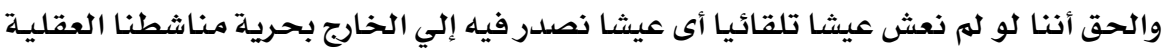

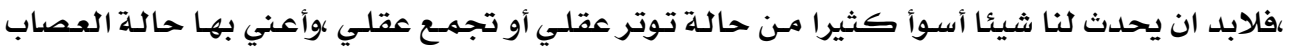
توان (Neurosis)

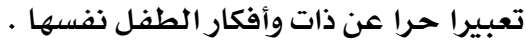
ثانيا التحريف:-

التحريف إحدى السمات المميزة لنحت الأطفال، لذا يلجأ الطفل إلى التحريف في الوصول

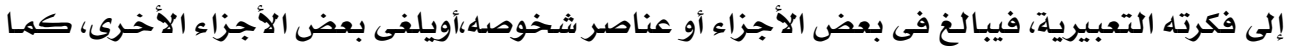

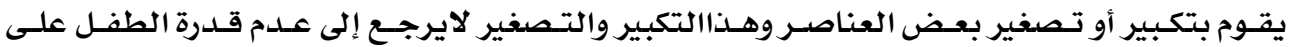

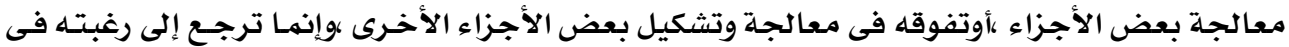

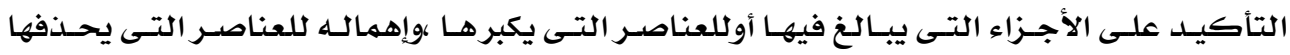

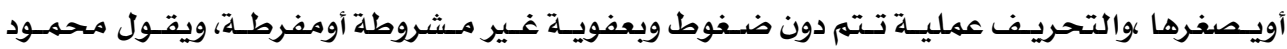

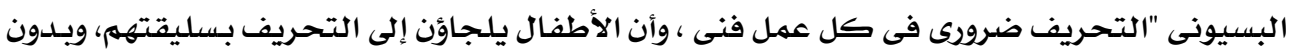

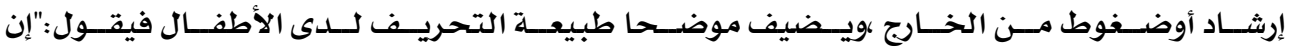
غالبيةالتلاميذ بعيدون كل البعد عن التقليد الحرفى لنقل الطبيعة "r.

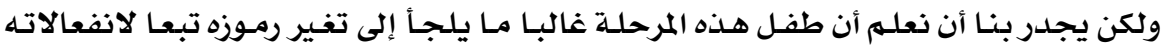

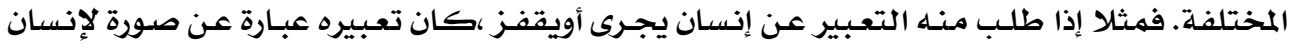

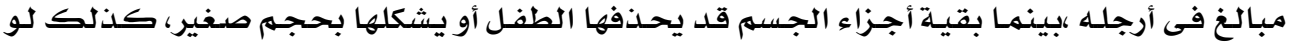

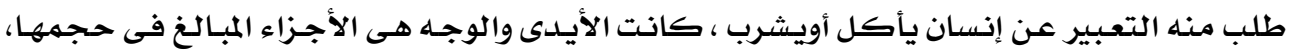

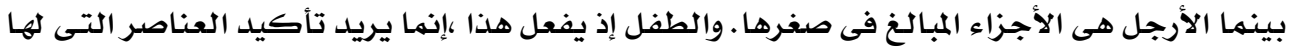
قيمة بالنسبة له،ويقلل من قيمة العناصر التى لا يشعر بأهميتها في أثناء التهب التعبير.

2 - Herbert Read, "The advanced Montessori Method, London, 1918, P 304- 306.

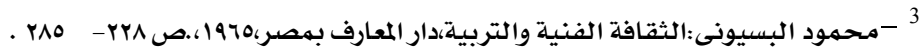




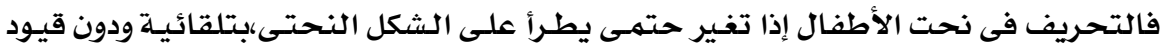

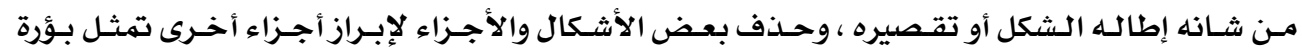

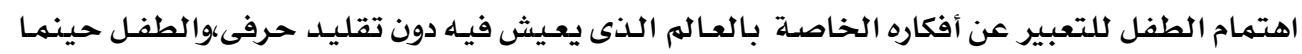

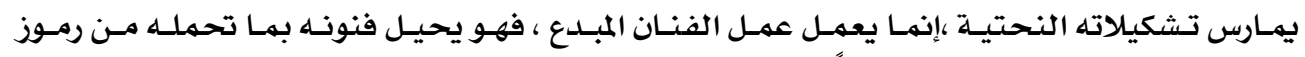

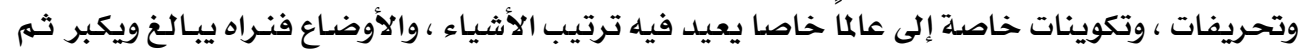

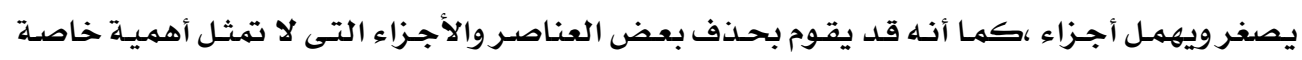

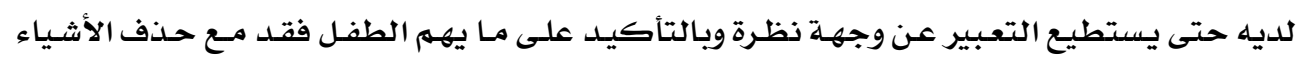

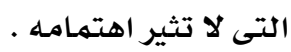

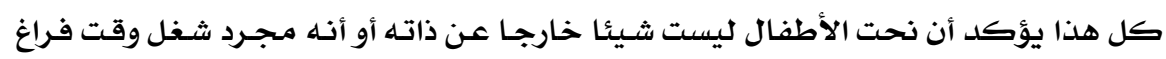

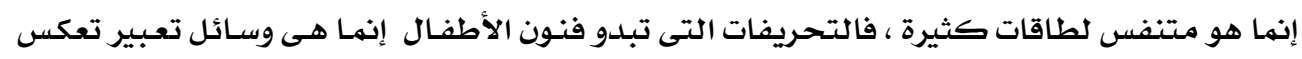

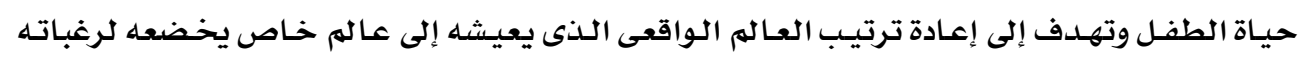

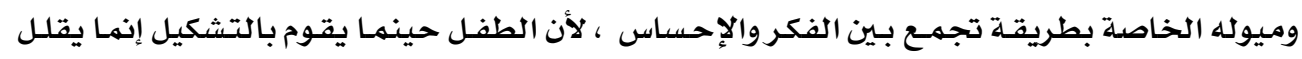

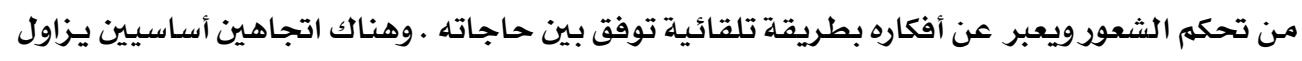

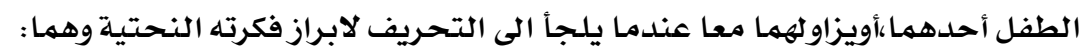

$$
\text { ا ـ التحريف لغرض زخرفى:- أحها }
$$

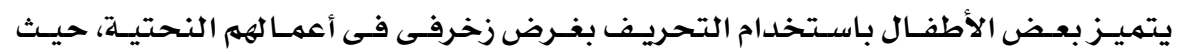

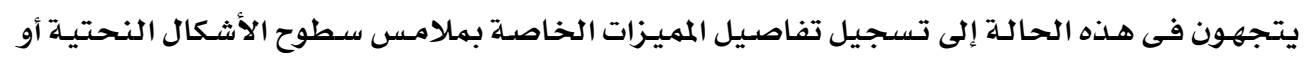

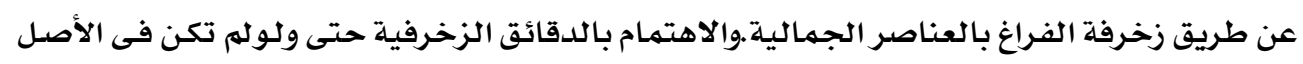

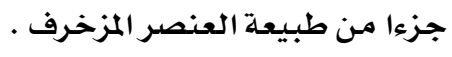

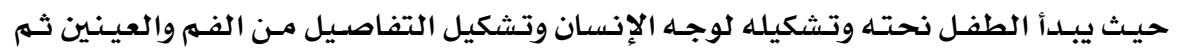

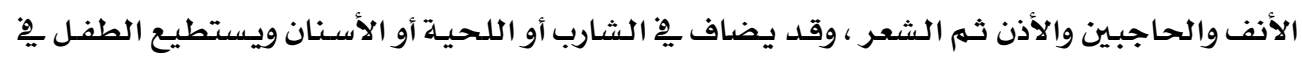

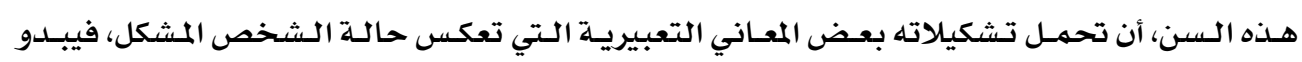

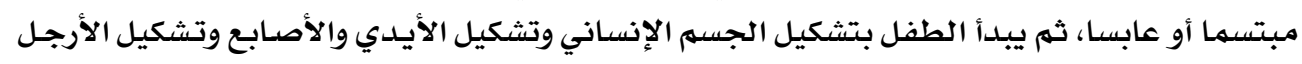

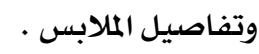

$$
\text { r. التحريف لغرض تعبيرى :- تلفيل }
$$

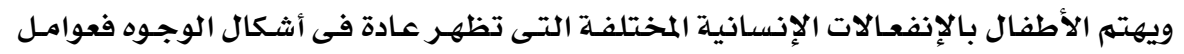

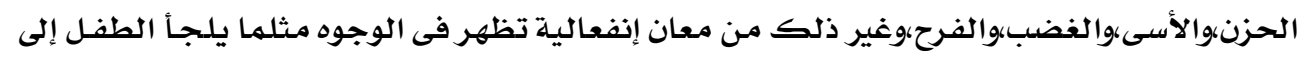

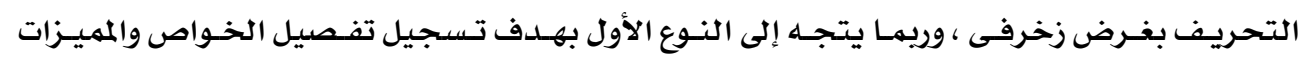

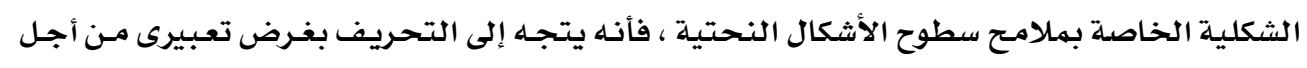

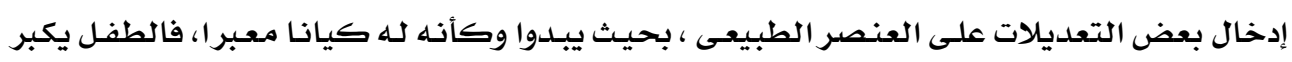

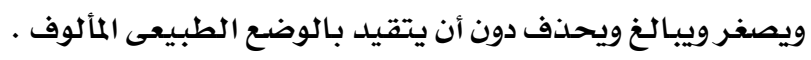




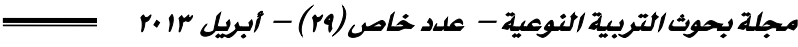

"فالتحريف فى نحت الأطفال يـرتبط بحتميـة مـا يختلج فى نفسـه ويؤثر فى ذاته بطريقـة

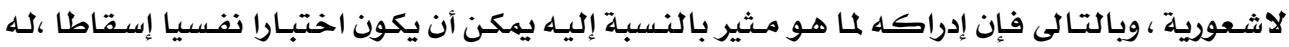

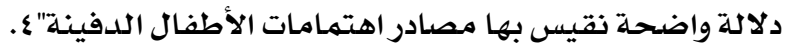

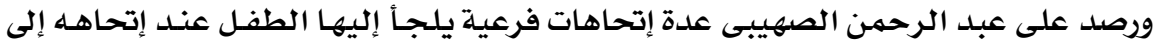

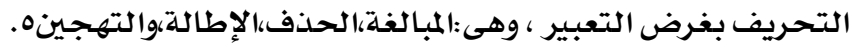
أ- المبالغة

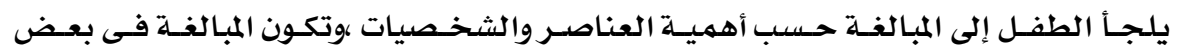

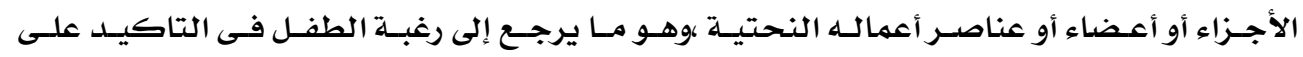

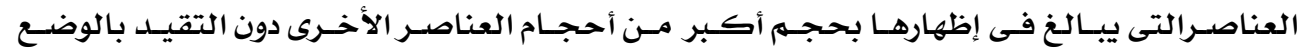
الطبيعى التعارف عليه.

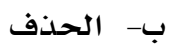

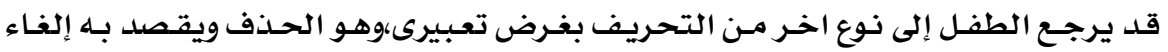

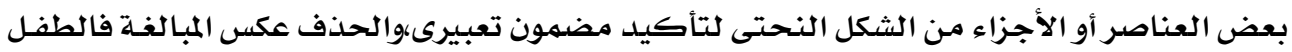

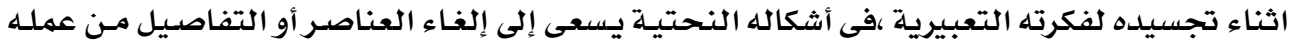

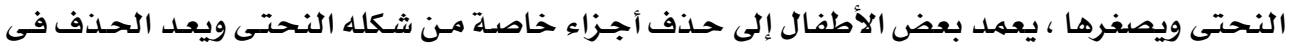

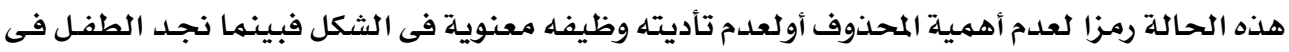

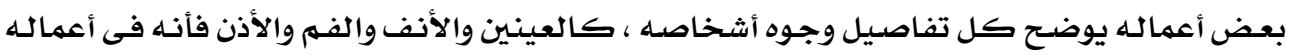

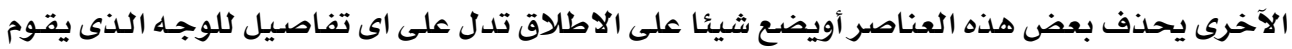
بتشكيله .

ج- الإطالة

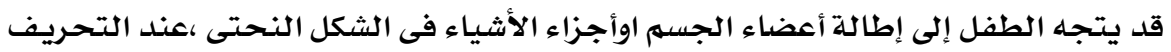

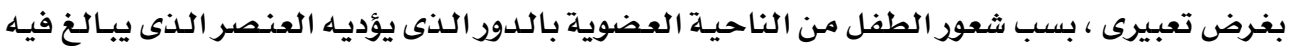

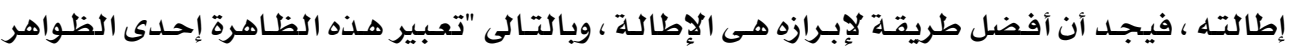

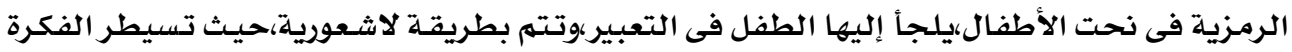

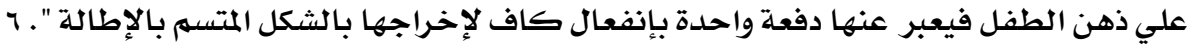

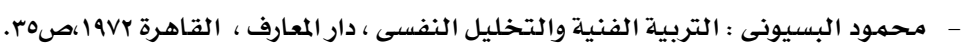

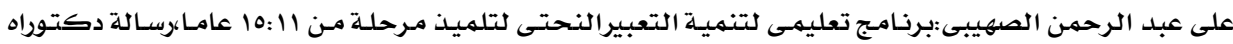

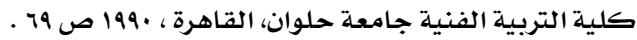

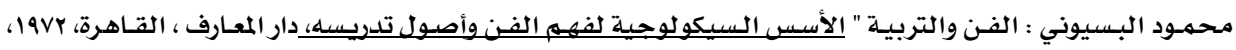




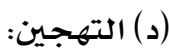

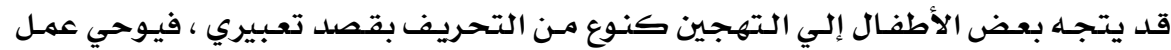

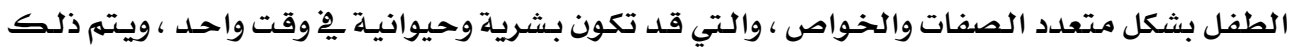

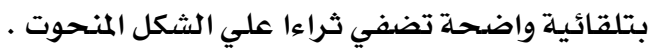

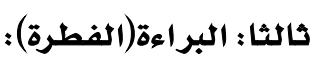

وهي صفة قد نقول عليها (سـاجة) ولكن ليست جميـع تشكيلات الأطفـال سـاذجة حيـث أن

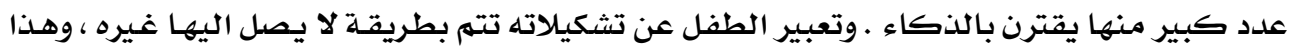
يسهي بالصدق الشعري وقد تم التعبير عنده.

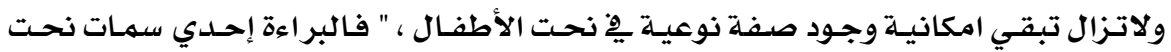

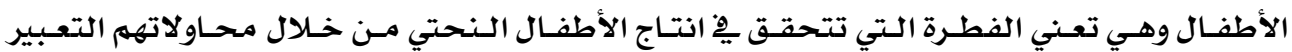

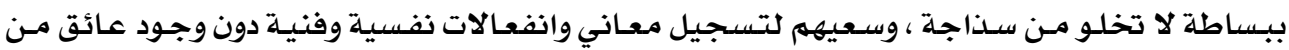

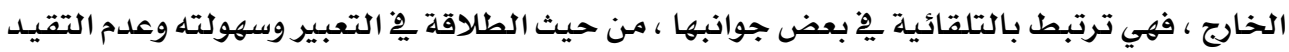

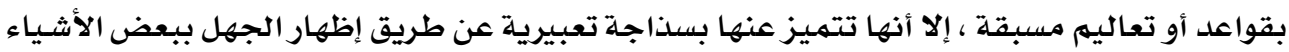

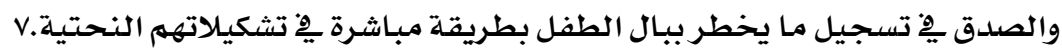

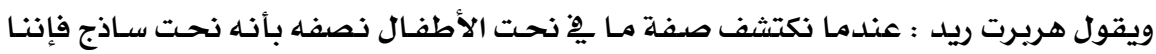

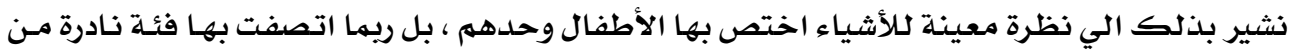

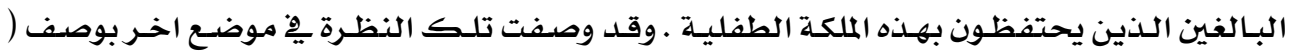

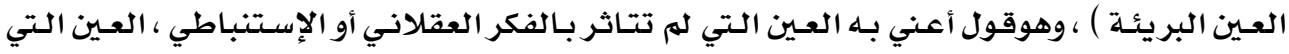

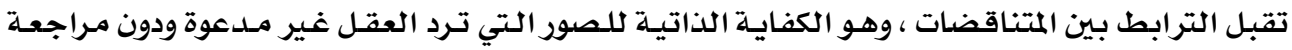

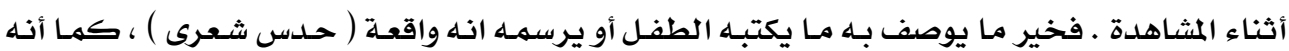

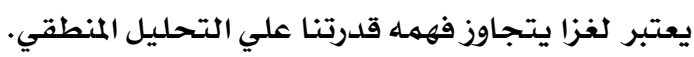

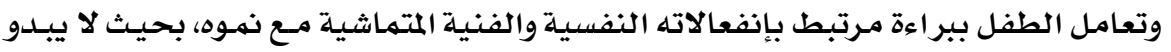

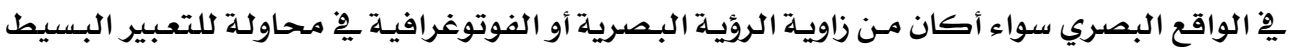

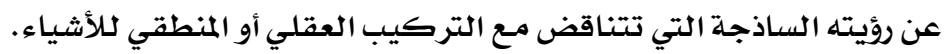
لذلك يمكن القول : أن البراءة يِ نحت الطفل هي صفة الفطرة التي تميز انتاجهم النـحتي

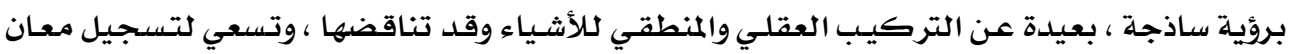

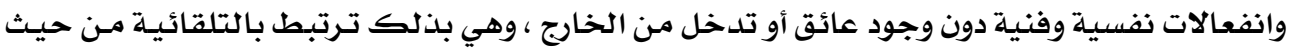

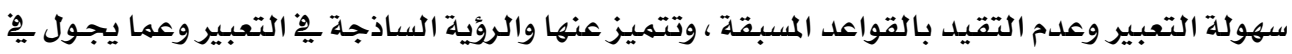
نفس الطفل بـدون عائق وبشكل حر.

7 عماد علي حسن : التلقائية يِّ فن النحت ، ماجستير ، كلية الفنون الجميلة ، جامعة حلوان ،997، ص1919 


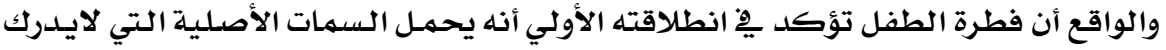

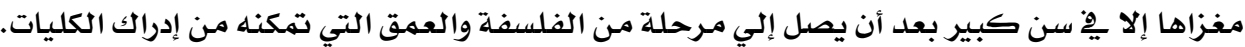
وقـد لاحـظ يعـض العلهـاء أن هنـاك طـابعين مميـزين للأسـاليب بوجـه عـام : الطـابع الاول

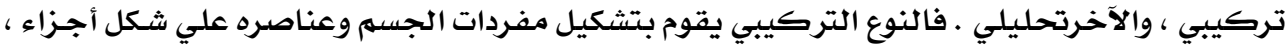

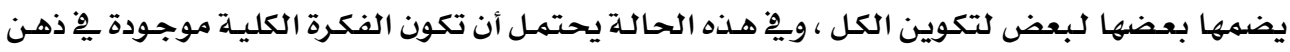

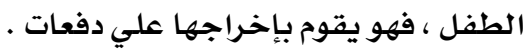

والطابع الثانى تحليلي ، فهو يبدأ بالكتلة الكلية ينحت فيها التفاصيل ويزيل منها لـانيا ، ويشكل

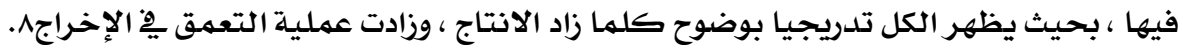
ويضيف فيكتـور لونفليـد :" أن الطـابع التركيبي لمنحوتـات الأطفـال هـي الطريقـة العامــة

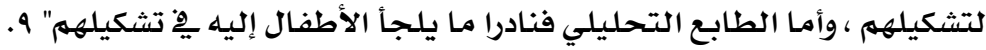

\section{خامسا : الطبيعة الهندسية:}

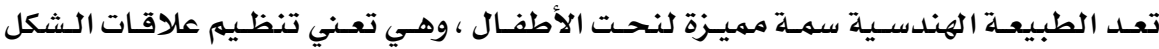

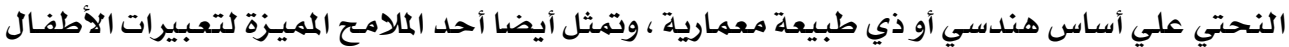

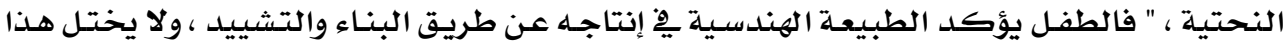

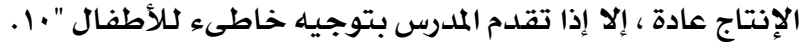

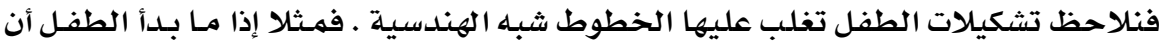

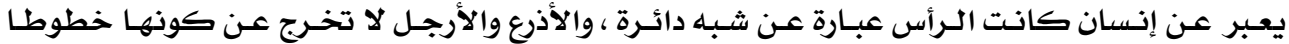

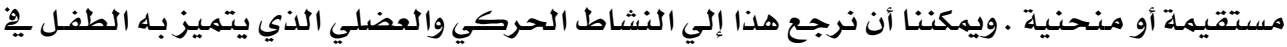
هذه السن. ويـري محمهـود البـسيوني " أنـه يهــن التعـرف علـي الفـارق بـين تعبير طفل وآخـر مـن خـلال

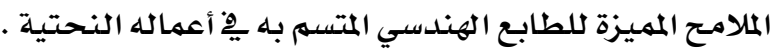

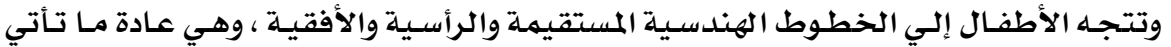

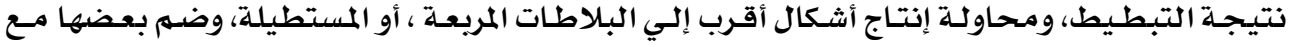

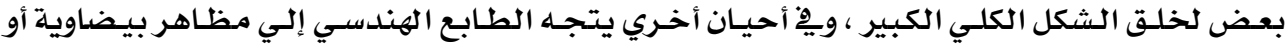

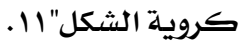

" :محمود البسيوني : نحت الأطفال دراسة مقارنة للنحت الشعبي والنحت القديم والحديث تطبيقات تربوية، دار المعارف ، القاهرة 1979، 198،

9 - Viktor Lowenfeld: Your Child and his Art, The Macmillan Co., New York, 1960, p99.

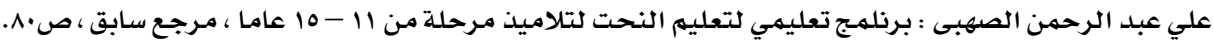

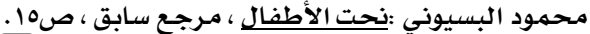




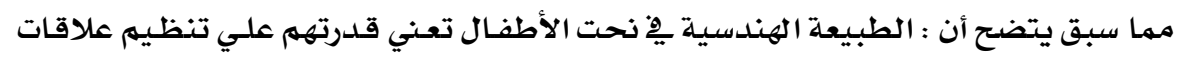

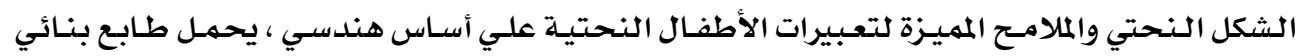
هندسي.

$$
\text { سادسا :التعبير عن الذات : قادرات }
$$

قد يكون الدافع إلى التعبير الفنى المجسهم عند الأطفـال هوتعبيرا عن الذات فالطفل أثناء

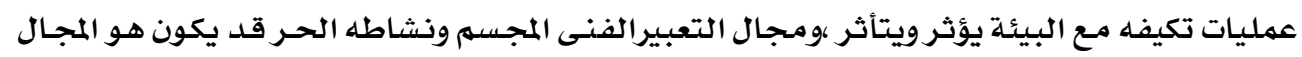

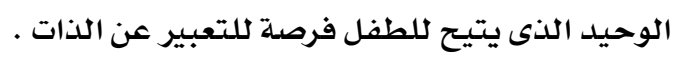

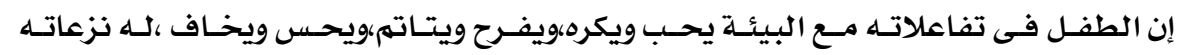

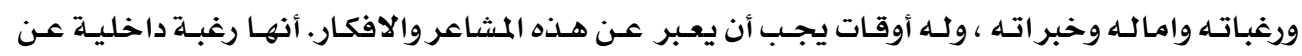

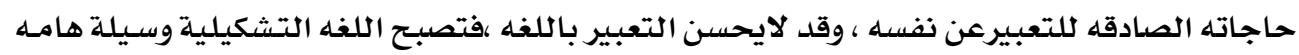
كلاتصال بالاخرين ، ونقل مايشغله.

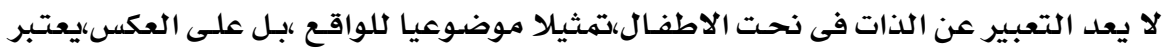

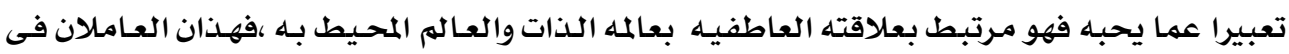

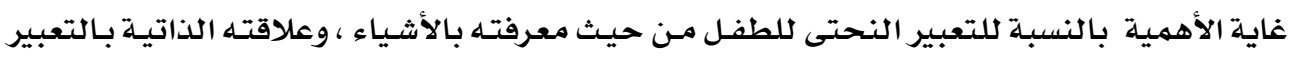

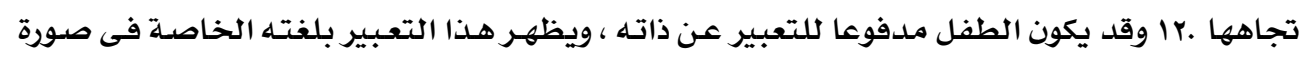

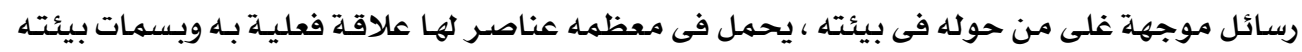

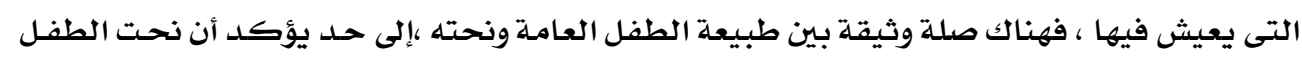

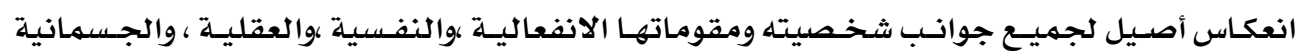

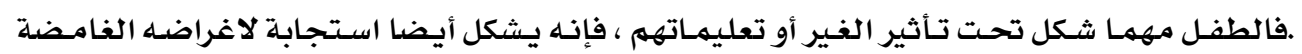

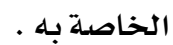

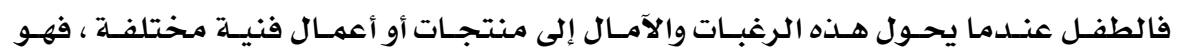

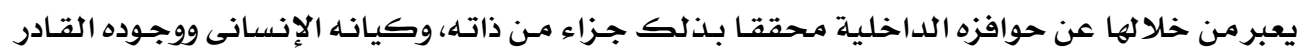

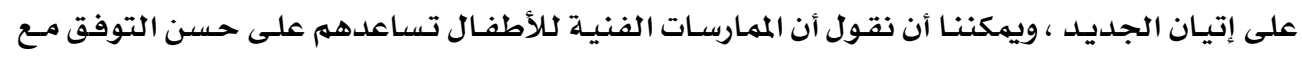

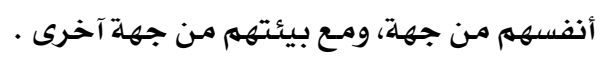

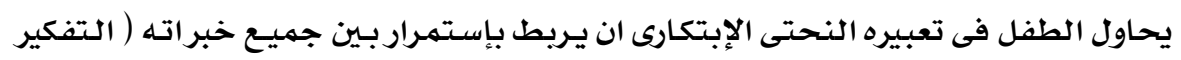

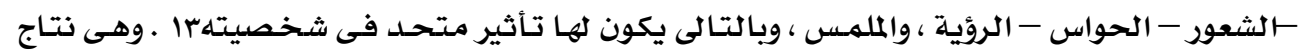

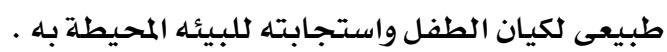

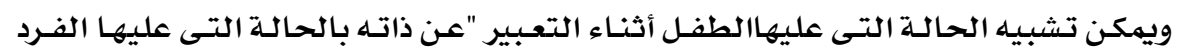

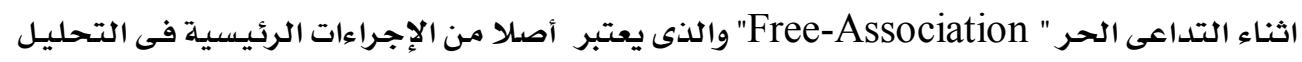

12 - Viktor Lowenfeld, "Op. Cit", P.5.

${ }^{13}$-Ibid, P, 6. 
النفسى والإرشاد النفسى ، فالطفل أثناء التعبير عن ذاته تحـت ظـروف تربويـة سليمة ،غير ضـاغطة ،

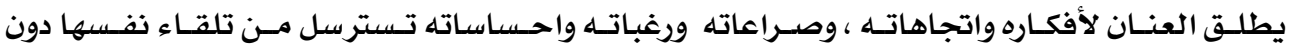

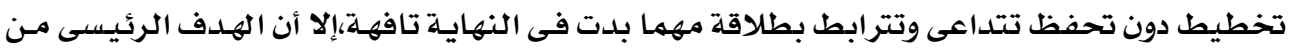

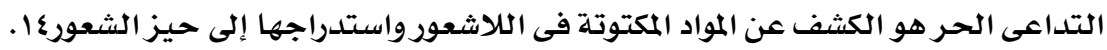

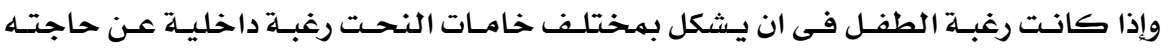

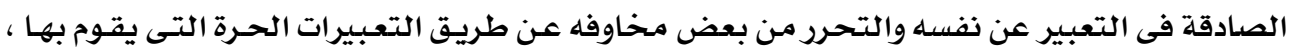

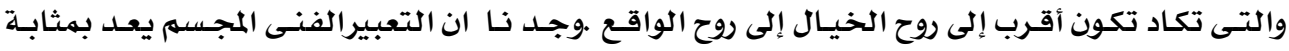

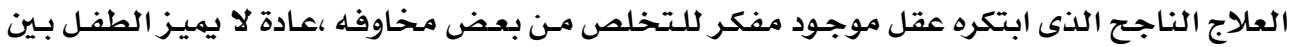

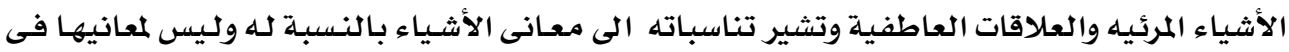

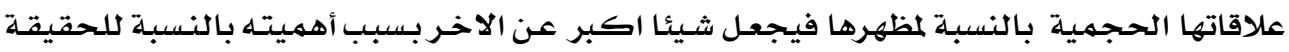
الموضوعية المجردة .

وعن طريق المعرفه الذاتية يمكن للطفل اكتساب الثقه فى تعبيره، فإذا زادت ثقتـه في نفسـه

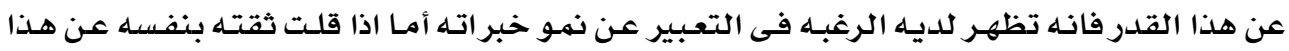

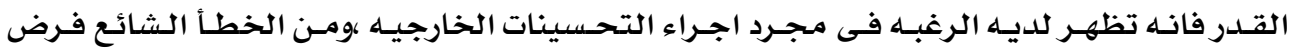

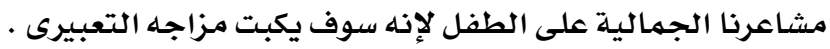

\section{سابعا التخيل : مابك}

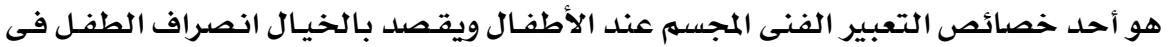

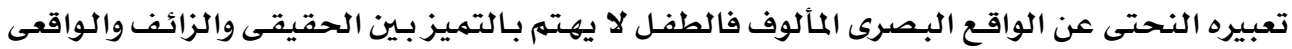

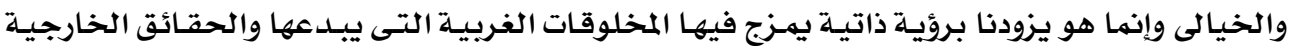

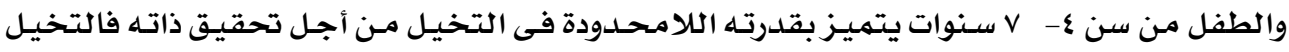

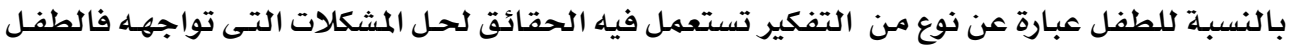

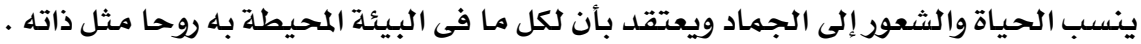
ويؤكد الفريد نورث هوايتهد " أهمية تبنى خيال الطفل لأن هـذا الخيـال هو مـدخل الطفل

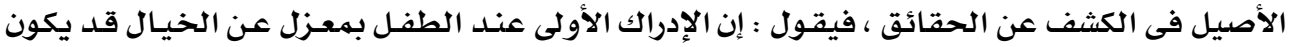

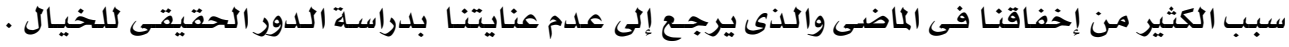

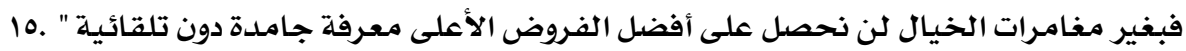

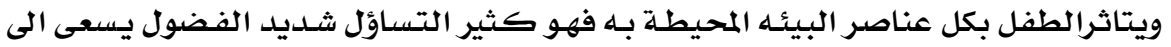

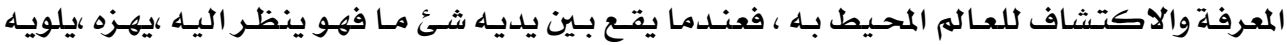

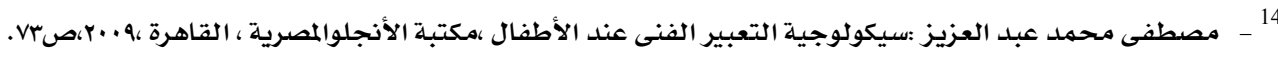

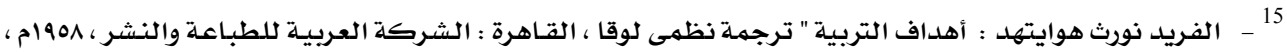


يحاول فتحهـ ليتعرف عليه والطفل ذا خيال حاد ،ولكن الخيال محددود في إطار البيئة التى يحيا فيها

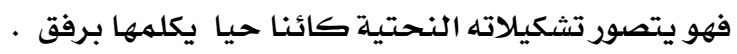

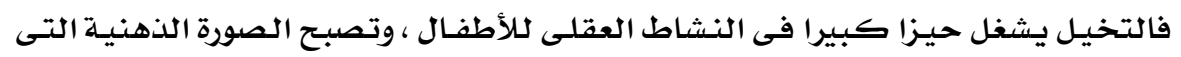

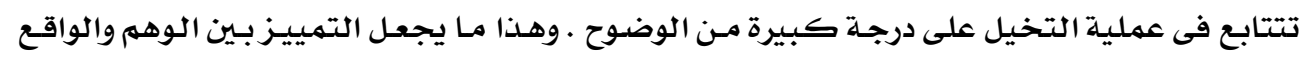

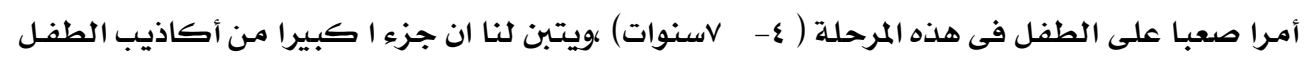

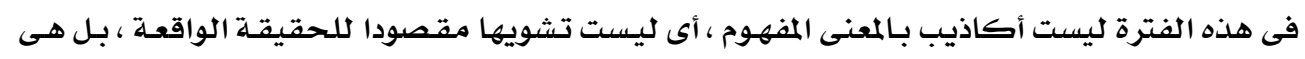

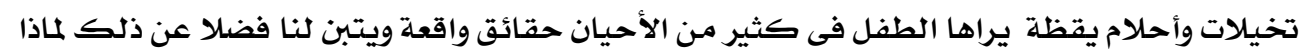

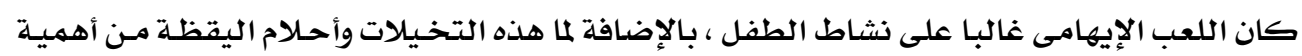

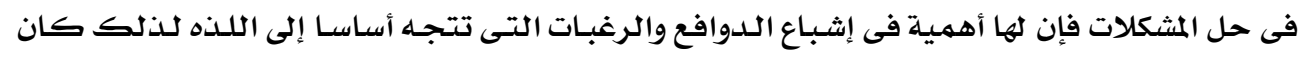

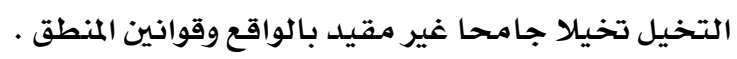

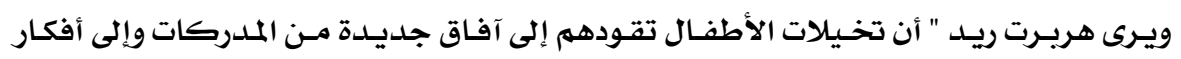

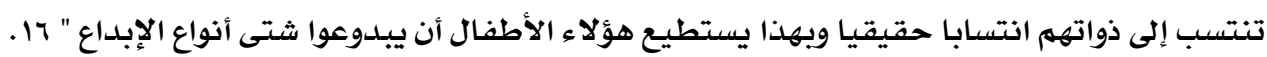

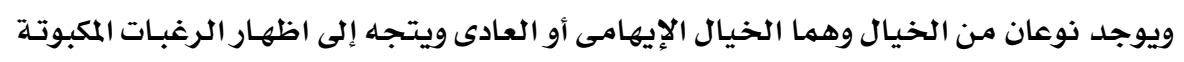

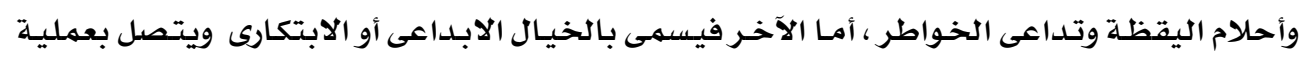

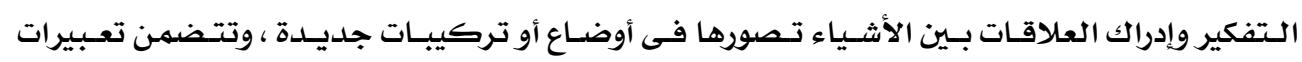

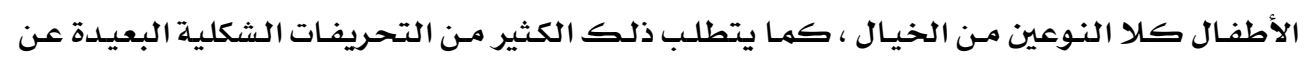
الواقع ·

ومما سبق يتضح ان مفهوم الخيال هو أحد خصائص التعبير الفنى المجسمه عند الأطفـال ،

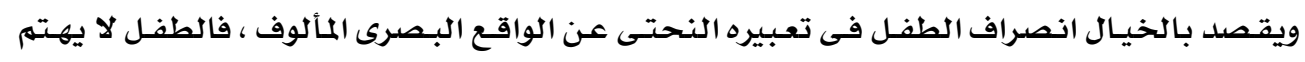

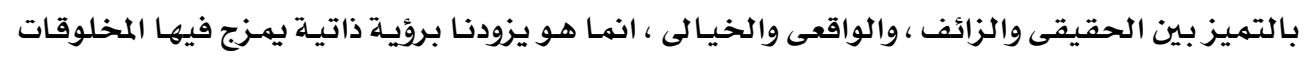

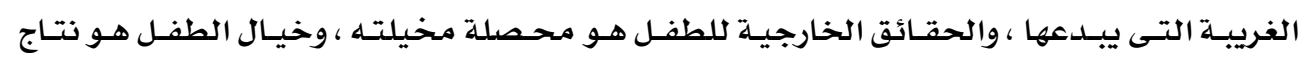

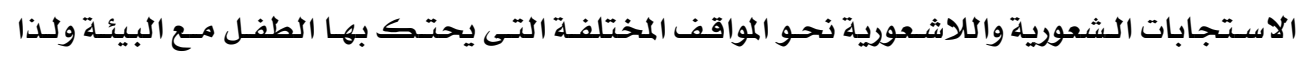

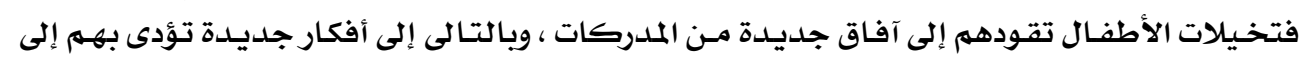

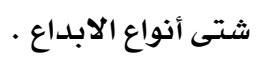

\section{ثامنا الرمزية}

ترتبط سمسة الرمزيـة لـدى الأطفـال بسـمة الخيـال ، وتعنى لجـوء الطفل إلى استخدام فكرة

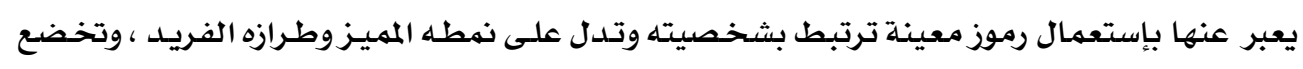

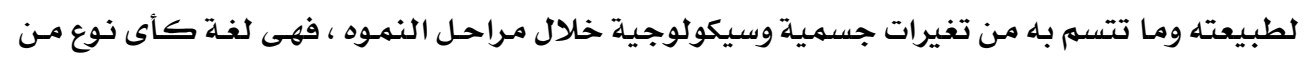

هربرت ريد : " الفن والمجتمع " ، ترجمة فتح البـاب عبد الحليم ، القـاهرة ، مطبعة شباب محمـد ، بدون تاريخ ، ص 


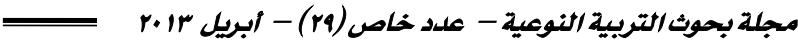

التعبير تنقل لنـا بالتـدريج تصوره عن الأحسداث المحيطة بـه ، وتفاعلـه معها أكثر مسن كونها وسسيلة لخلق شئ جميل .

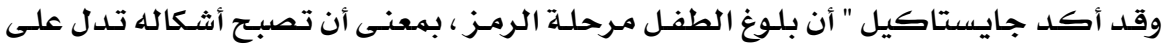

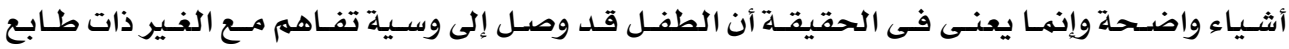

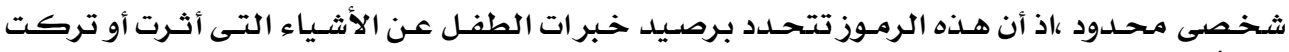

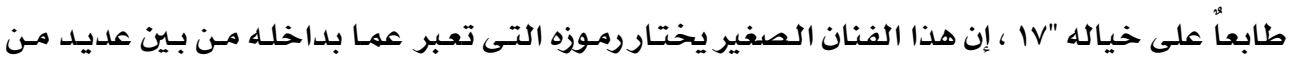

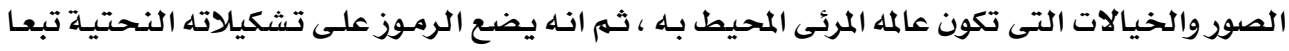
لأهميتها له .

والطفل يلخص خبر ته فى الحياه فى مجموعة من الرموز والأشكال البسيطة التى يستطيع

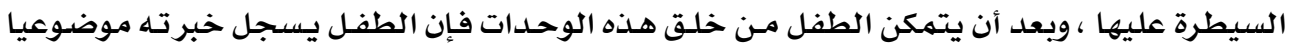

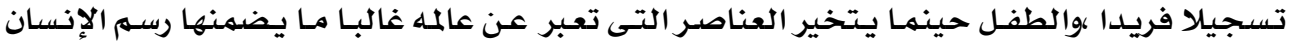

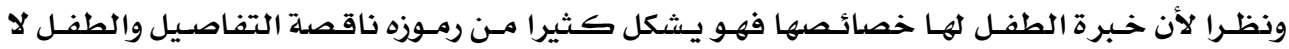

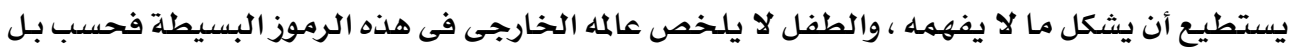

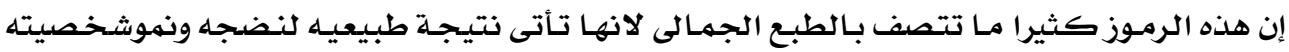
واستكمال قوته العضلية تدريجيا .

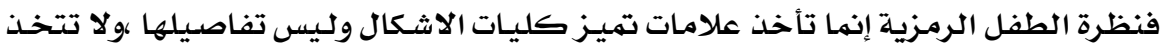

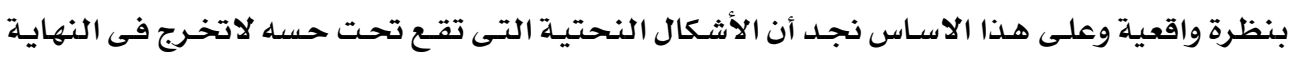

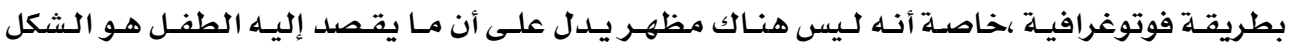
الطبيعى . بطربقه

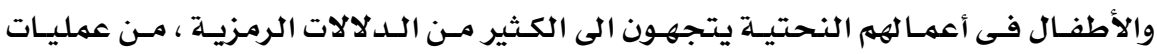

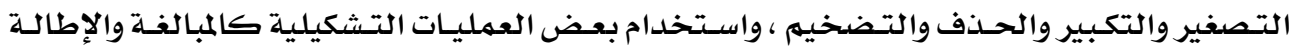

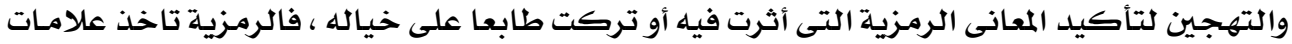

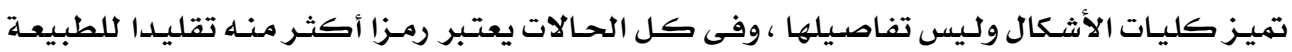

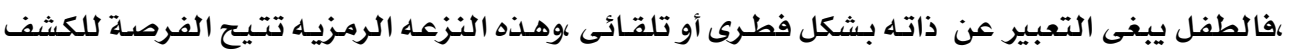

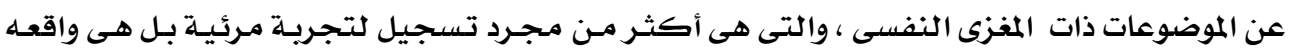
حيه لها معنى روحى يكسبها قيمتها الجمالية . والرمزز يعتبر مقنعا للطفل فى اللحظة التى يستخدمـه فيها وهو يعيد تكرار هـذا الرمـز بـين

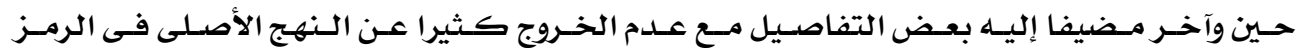
المستخلدم. 


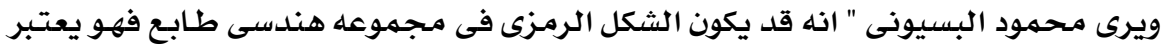

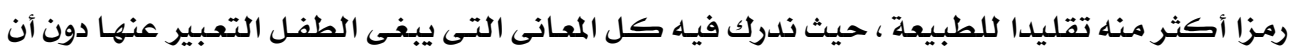

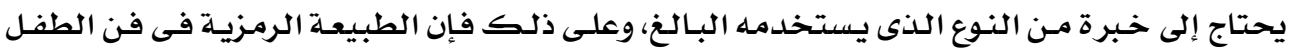

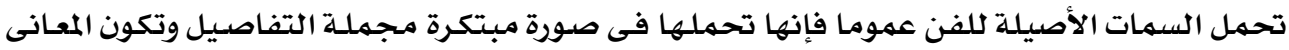

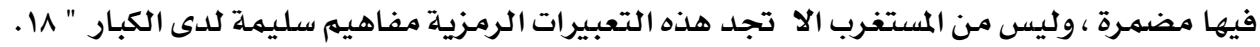

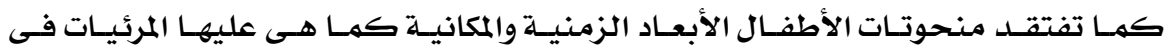
الطبيعة فالطفل يدرك الحقائق بطريقة غير مجزأة على هيئة سلسلة من المواقف المتتابعة مثلما تأثر

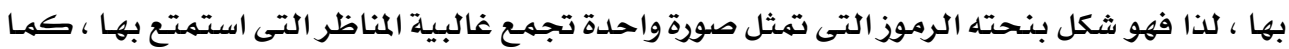

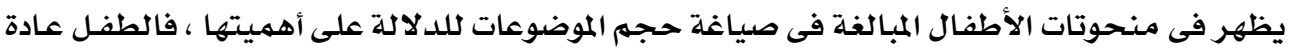

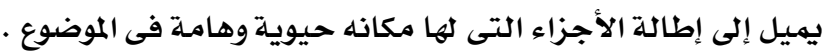

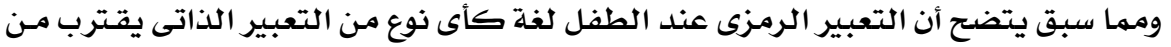

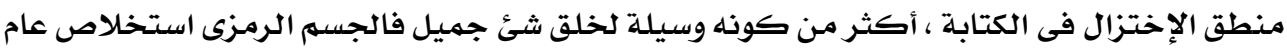

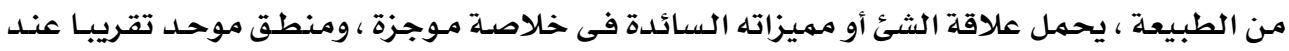
إدراك الطبيعة . من الطبيعة ،حتل 


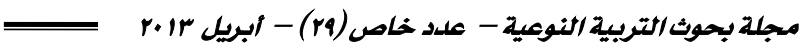

\section{المراجع والمصادر :}

ا. على عبد الرحمن الصهيبـى:برنامج تعليهى لتنميـة التعبيرالنحتى لتلميـذ مرحلـة مـن 10:11 عامـا،رسـالة دكتوراه كلية التربية الفنية جامعة حلوان، القاهرة ، •199.

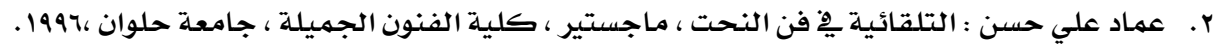
r. محمود البسيونى:الثقافة الفنية والتربية،دار المعارف بمصر،،1970 ـ ع. محمود البسيونى:التربية الفنية والتخليل النفسى ، دارالمعارف ،القاهرة I9Vr . ه. محمود البسيوني : الفن والتربية " الأسس السيكولوجية لفهم الفن وأصول تدريسـ، دار المعـارف ، القـاهرة، $.19 V Y$

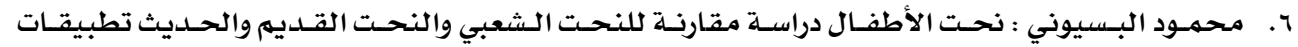
تربوية، دار المعارف ، القاهرة ، 1979 .

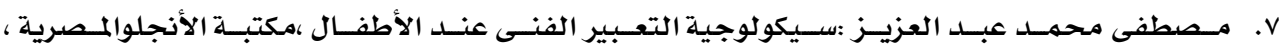

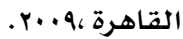

^. الفريد نورث هوايتهد : " أهداف التربية " ، ترجمة نظهى لوقا ، القاهرة : الشركة العربية للطباعة والنشر .1901 .

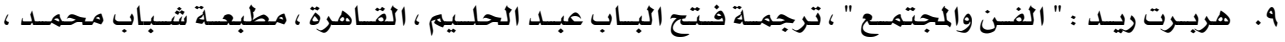
بدون تاريخ.

• . هربرت ريد : التربية عن طريق الفن ترجمة: عبد العزيز جاويد ،الهيئة العامة للكتاب ،القاهرة، 1999 .

11. Herbert Read, "The advanced Montessori Method", London, 1918.

12. Viktor Lowenfeld: Your Child and his Art, The Macmillan Co., New York, 1960 